\title{
Curriculum in biomedical optics and laser-tissue interactions
}

\section{Steven Jacques}

Steven L. Jacques, "Curriculum in biomedical optics and laser-tissue interactions," Proc. SPIE 9663, Eighth International Topical Meeting on Education and Training in Optics and Photonics, 96630N (6 October 2003); doi: $10.1117 / 12.2207352$

SPIE Event: Eighth International Topical Meeting on Education and Training in Optics and Photonics, 2003, Tucson, Arizona, United States 


\title{
Curriculum in biomedical optics and laser-tissue interactions
}

\author{
Steven L. Jacques \\ Biomedical Engineering, Oregon Health \& Science Univ., 20000 NW Walker Rd., Beaverton, OR 97006 \\ sjacques@bme.ogi.edu
}

\begin{abstract}
A graduate student level curriculum has been developed for teaching the basic principles of how lasers and light interact with biological tissues and materials. The field of Photomedicine can be divided into two topic areas: (1) where tissue affects photons, used for diagnostic sensing, imaging, and spectroscopy of tissues and biomaterials, and (2) where photons affect tissue, used for surgical and therapeutic cutting, dissecting, machining, processing, coagulating, welding, and oxidizing tissues and biomaterials. The courses teach basic principles of tissue optical properties and light transport in tissues, and interaction of lasers and conventional light sources with tissues via photochemical, photothermal and photomechanical mechanisms. More information can be found at http://www.bme.ogi.edu/biomedicaloptics/.
\end{abstract}

-2003 Optical Society of America

OCIS codes: (170.0170) Medical optics and biotechnology

\section{Introduction}

The uses of lasers and light in medicine and biology are undergoing an explosive growth. The availability of optical fibers, diode and solid-state lasers, superluminescent diodes, CCD cameras, and new photonic detectors has spurred interest in new applications and development of theoretical understanding of how photons move through and interact with tissues and biomaterials. Today, a body of techniques and associated theoretical modeling is available for engineering design and experimental work.
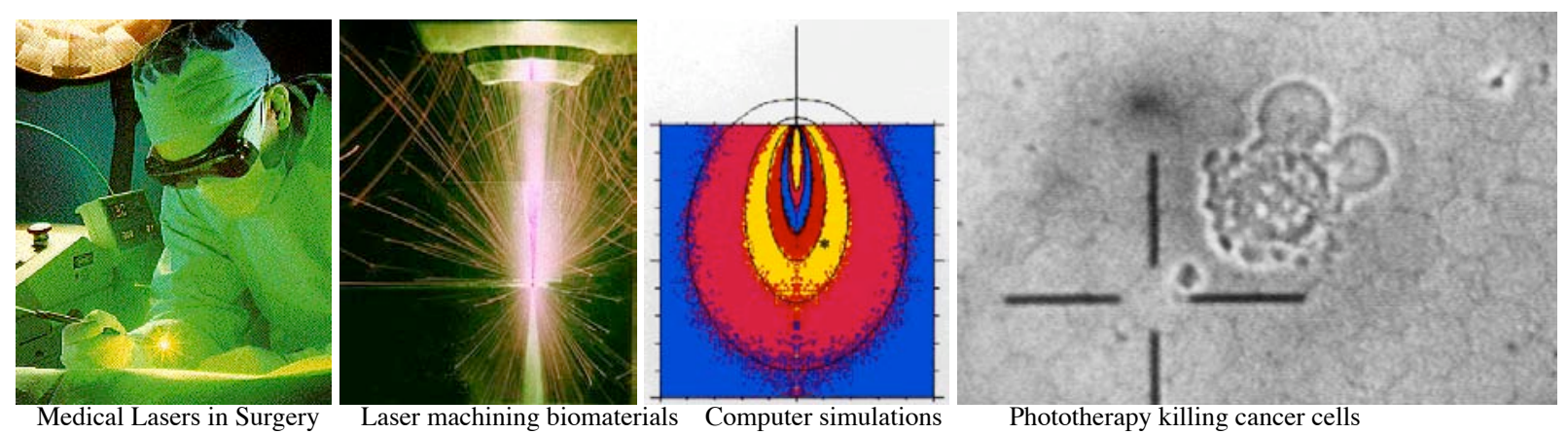

The curriculum consists of

Biomedical Optics 1: Tissue Optics

Biomedical Optics 2: Laser-Tissue Interactions

Biomedical Optics 3: Engineering Design

Computational approaches to light transport in biological tissues

Computational approaches to laser interaction with biological tissues

Physical and Geometrical Optics

Optical Non-destructive Evaluation

Eighth International Topical Meeting on Education and Training in Optics and Photonics, edited by Barry L. Shoop, Grover Swartzlander Jr., Proc. of SPIE Vol. 9663, 96630N

(C) 2003 SPIE, OSA, ICO · doi: 10.1117/12.2207352 


\section{Tissue Optics}

The course introduces the origins of tissue optical properties, i.e. absorption, scattering, and refractive index. The time-resolved transport of photons is introduced using Monte Carlo simulations to illustrate behavior and diffusion theory to summarize photon transport. Monte Carlo simulations mimic the movement of individual photons through a light-scattering tissue. The Fourier transform of the time-resolved computations yields the frequency-domain descriptions that describe the transport of light from sources modulated at various frequencies. The temporal integration of the time-resolved transport yields the steady-state solutions, the most commonly used form of optical measurement. Hence, the relationship between the time-resolved, the frequency-domain, and the steady-state solutions are illustrated by both Monte Carlo simulations and by diffusion theory. An introduction to spectroscopy and imaging is presented illustrating the uses of tissue optics.

The basics of laser safety are taught before the students are allowed into the laboratory. The key issue is eye safety, with consideration of skin exposures as well. The course includes a laboratory in which the students assemble optical and laser experiments to demonstrate the principles learned in classes.

The introductory course is Biomedical Optics 1: Tissue Optics. The follow-up course is Computational approaches to light transport in biological tissues which introduces time-resolved finite-difference modeling and considers Monte Carlo simulations in more detail. Boundary conditions (such as an air-tissue surface or a glass-tissue interface) are considered. Tissue heterogeneities (such as blood vessels or tumors) are considered by the introduction of perturbation theory.

\section{Laser-Tissue Interactions}

The course introduces the interaction of lasers and conventional light sources with tissues and biomaterials. The topics are photochemical mechanisms of interaction, and examples include photodynamic therapy (a light-activated chemotherapy for cancer and other pathology) and light-activated adhesives; photothermal mechanisms of interactions, and examples include photocoagulation, hyperthermia, laser welding of tissues; photomechanical mechanisms of interactions, and examples include tissue cutting, vaporization, cavitation, spallation and evaporative dessication of tissues. The course makes use of optical and thermal diffusion theory and the Arrhenius formulation for thermal damage.

The introductory course is Biomedical Optics II: Laser-Tissue Interactions. The follow-up course is Computational approaches to laser interaction with biological tissues which introduces the use of compartmental modeling of coupled differential equations to model photochemical processes, and time-resolved finite-difference modeling to model thermal and ablative processes.

\section{Engineering Design}

This course is an especially popular offering. The students are asked to organize themselves into a group with a $\mathrm{CEO}$, a chief financial officer, a science officer, a marketing officer, a manufacturing officer, and a regulations/safety officer. This group will develop a business plan for a particular product. The group interviews guest experts (eg., a physician in some specialty), develops a product within a particular topic area (eg., photochemical effects), conducts an demonstration experiment in the lab, prepares a business plan, and presents the plan to an audience of venture capitalists (portrayed by the faculty). The project requires the students to understand the basic mechanism of interaction, be aware of the field of medical practice, utilize their engineering skills acquired in previous classes, and consider other aspects of a project such as ease of manufacture, customer interest in the product, and safety issues. In the past, the students have organized one project every two weeks for a total of five projects that were defended. In this way, the students could play different roles. Although they have successfully done this, it might be better to have only 3 projects and let the students work 3 weeks on each project. 


\section{Physical and Geometrical Optics}

The course introduces first-order Gaussian optics and thin-lens system layout. Photometric theory is applied to optical systems. The eye, magnifier, microscope, matrix optics, nature of Seidel aberrations are considered. Scalar diffraction theory; Fresnel and Fraunhofer diffraction are presented. Interferometry is introduced.

\section{Optical Non-Destructive Testing}

This course is meant to be a graduate level course aimed at introducing the field of optical NDE to engineering students. The course focuses primarily on coherent light techniques such as interferometry, holography, and laser speckle methods. Morié, photo-elastic, and structured light methods are also discussed. Specific applications to biomedical engineering, semiconductor, and electronic materials are presented 